\title{
Evidence of Chemical Complexity and Laser-Driven Autocatalysis in Type IA FBGs
}

\author{
George Simpson ${ }^{\mathrm{a}}$, Kyriacos Kalli ${ }^{\mathrm{b}}$, John Canning ${ }^{\mathrm{c}}$ and Amedee Lacraz ${ }^{\mathrm{b}}$ \\ ${ }^{a}$ Technology Consulting, Deloitte Touche Tohmatsu, Perth, Western Australia \\ ${ }^{b}$ Nanophotonics Research Laboratory, Cyprus University of Technology, Limassol, Cyprus \\ ${ }^{c}$ interdisciplinary Photonics Laboratories, School of Chemistry, The University of Sydney, Australia \\ kyriacos.kalli@cut.ac.cy
}

\begin{abstract}
We observe the first chemical complexity for Type IA FBG growth under prolonged UV laser exposure. Out-of-phase oscillatory behaviour in $\mathrm{GeOH} / \mathrm{SiOH}$ formation provides evidence of laser-driven autocatalysis and chemical origins for grating formation.

OCIS codes: (060.0060); (060.3735); (060.3738)
\end{abstract}

\section{Introduction and experimental results}

Type IA or Type $1 p$ fibre Bragg gratings (FBG) are formed in hydrogenated germanosilicate fibres at room temperature [1,2], as combined hydrogenation and UV-laser fluence conditions induce local material changes that lead to large increases in the Bragg wavelength $\left(\lambda_{\mathrm{Bragg}}\right)$ and mean index $\left(\Delta n_{\mathrm{eff}}\right)$ of the fibre core during FBG inscription (Fig. 1). The modulated index change $\left(\Delta n_{\bmod }\right)$ shows oscillatory growth behaviour and the overall grating growth (the increase in $\Delta \lambda_{\text {Bragg }}$ ) is correlated with absorption features that appear at $\sim 1400 \mathrm{~nm}$ linked to the formation of both $\mathrm{SiOH}$ and $\mathrm{GeOH}$ groups, Fig. 1 [3]. For highly doped fibres (Ge or $\mathrm{B} / \mathrm{Ge}) \Delta \lambda_{\text {Bragg }} \sim 15-20 \mathrm{~nm}$, translating to an increase in the effective core index of $\Delta n_{\text {eff }} \sim 2 \times 10^{-2}$ [4]. We believe that these index modifications must reflect material changes within the core and core-cladding regions, consistent with net structural relaxation and hence stress changes at the core-cladding interface. The extraordinarily large laser fluence further supports an annealing-like relaxation. Such changes can exceed the local polarisability changes around altered or induced microscopic defect sites alone. Given that the formation of $\mathrm{SiOH}$ and $\mathrm{GeOH}$ species can provide an indication of net energy imparted to the network, high temperature thermal annealing can lead to auto-oscillatory behaviour as hydrogen out-diffuses [5]. In recent studies we did not observe this in Type IA FBG formation in Ge-doped fibre suggesting that the inscription temperatures (between 100 and $200^{\circ} \mathrm{C}$ ) induced by UV excitation and UV-induced bond breaking proved ineffective and concluded that auto-oscillatory catalysis did not occur [6]; new data analysis show conclusively otherwise.

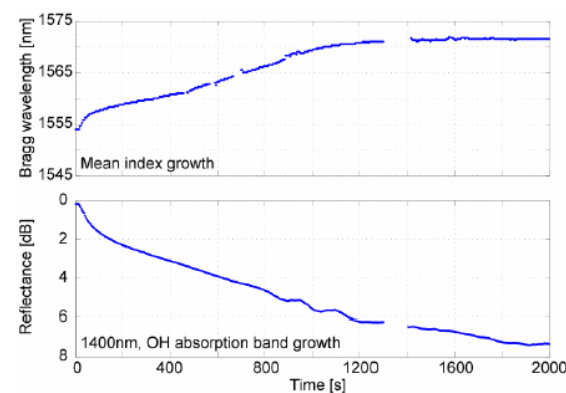

Fig. 1. Mean index change (or IA maturity) and the $1400 \mathrm{~nm}$ absorption band under UV exposure.

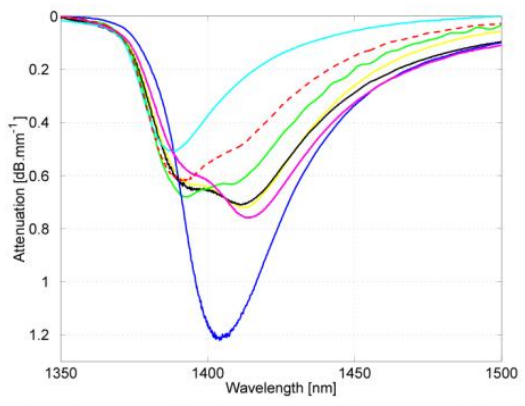

Fig. 2. (a) $\mathrm{OH}$ bands created in the optical fibres, partially listed in Table 1 , by uniform exposure to UV radiation.

Table 1. Summary of the absorption band peaks and dopant levels for the fibres tested. U - Unidentified.

\begin{tabular}{c|ccc:|cc|cc}
\hline \multirow{2}{*}{ Fibre reference } & Manufacturer & $\begin{array}{c}\text { Fig. } 2 \text { colour } \\
\text { convention }\end{array}$ & $\begin{array}{c}\text { Fibre } \\
\text { type }\end{array}$ & \multicolumn{2}{|c|}{ Main peak } & \multicolumn{2}{|c}{ Secondary peak } \\
nm & $\mathrm{dB} / \mathrm{mm}$ & $\mathrm{nm}$ & $\mathrm{dB} / \mathrm{mm}$ \\
\hline SMF28 & Corning & Cyan & STD & 1388 & 0.51 & $\mathrm{U}$ & $\mathrm{U}$ \\
PS1250/1500 & Fibercore & Blue & $\mathrm{B} / \mathrm{Ge}$ & 1404 & 1.22 & 1425 & $\mathrm{U}$ \\
SD079-00B & Fibercore & Green & $\mathrm{Ge}$ & 1393 & 0.68 & 1408 & 0.63 \\
\hline
\end{tabular}

We propose that if coupling exists between $\mathrm{SiOH}$ and $\mathrm{GeOH}$, their absorption bands will oscillate out of phase, and follow an exponential decay profile as free $\mathrm{OH}$ or $\mathrm{H}$ hops between sites and slowly diffuses out of the fibre core. For this to occur, there must be an equivalence between $\mathrm{GeOH}$ and $\mathrm{SiOH}$ free energies that is achieved when their free 
energy of formation is lower than the surrounding energy bath of the network. At room temperature this is impossible and temperatures above $500^{\circ} \mathrm{C}$ are necessary [5]. As the effective temperature is $\sim 100^{\circ} \mathrm{C}$, UV laser induced bond breaking would have to reduce the energies of $\mathrm{Ge}$ and $\mathrm{Si}$ sites to allow much lower phonon energies to release $\mathrm{OH}$ or $\mathrm{H}$, with index linked to differences between the index polarisability at the $\mathrm{GeOH}$ and $\mathrm{SiOH}$ sites.

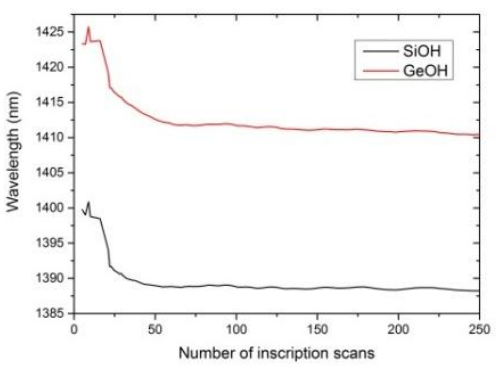

Fig. 3. (a) Evolution of $\mathrm{SiOH}$ and $\mathrm{GeOH}$ absorption band peak wavelengths with laser scan number $-N C C$

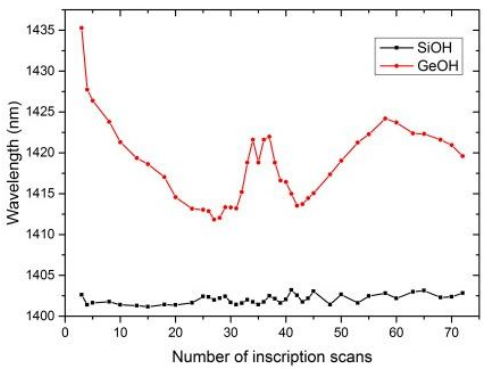

Fig. 4. (a) $\mathrm{SiOH}$ and $\mathrm{GeOH}$ absorption band peak wavelengths vs laser scan number $-C C$.

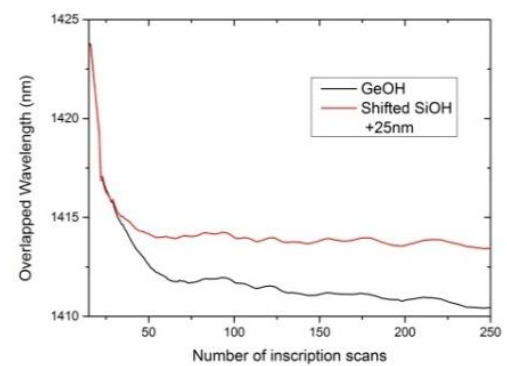

(b) Superimposed $\mathrm{SiOH} / \mathrm{GeOH}$ curves to compare growth and equilibrium with laser scan number $-N C C$.

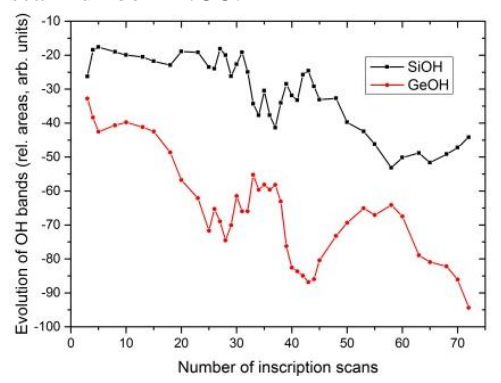

(b) Evolution of $\mathrm{SiOH} / \mathrm{GeOH}$ absorption band areas with laser scan number $-C C$.
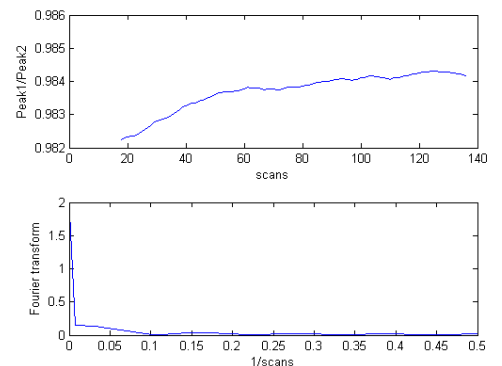

(c) Ratio of $\mathrm{SiOH} / \mathrm{GeOH}$ absorption band peak wavelengths vs scan number and their FFT, excl out-of-phase oscillations $-N C C$

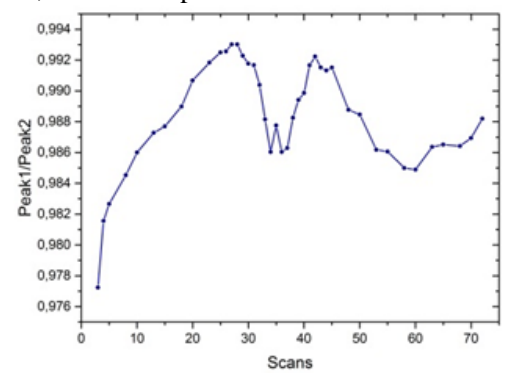

(c) Ratio of $\mathrm{SiOH} / \mathrm{GeOH}$ absorption band peak wavelengths vs scan number $-C C$.

Fig. 3 shows there are no chemical complexity (NCC) and autocatalysis processes for Ge-doped fibre (SD079-00B), despite the role of $\mathrm{OH}$ in the large dc shift and possible role as a photorefractive component generating the low thermal stability of the modulated index. Clearly the background energy is too low to equalise the energy levels of the general $\mathrm{GeO}$ and $\mathrm{SiO}$ bond sites for $\mathrm{OH}$ formation. The combined UV bond breaking and effective heating are unable to provide this energy. However, the $\mathrm{B} / \mathrm{Ge}$ codoped fibre (PS1250/1500) does show that autocatalysis is present and contributes to Type IA grating formation (Fig. 4); the changes are observed to be out-of-phase as anticipated and consistent with a diffusion-mediated hopping process. The observed index modulation is a reflection of the exchange between the $\mathrm{OH}$ species, clearly showing the presence of chemical complexity $(C C)$. This exciting new development shows the importance of dopants in fine tuning chemical complexity within an optical fibre offering unprecedented control over the final index stability. This marks a major scientific milestone, establishing the topical waveguide as an exciting new platform for complexity studies including chaotic material behaviour.

\section{Acknowledgement}

The views expressed in this paper do not represent an official position of Deloitte Touche Tohmatsu.

The experimental work, which has been reinterpreted here, was performed at Aston University's Photonics Research Group. We acknowledge their considerable contribution, the generous funding of the Engineering and Physical Research Council, Indigo Photonics and BAE Systems and the sound council of Profs Ian Bennion and Lin Zhang.

\section{References}

[1] Simpson A.G., Kalli K., Zhou K., Zhang L., Bennion I., "Formation of type IA fibre Bragg gratings in germanosilicate optical fibre", Elect. Lett., 40(3), 163-164 (2004)

[2] Canning J., "Fibre gratings and devices for sensors and lasers", Lasers \& Photon. Rev., 2(4), 275-289 (2008)

[3] Kalli K., Simpson A.G., Zhou K., Zhang L., Bennion I., "Tailoring the temperature and strain coefficients of type I and type IA dual grating sensors - the impact of hydrogenation conditions", Meas. Sci. Technol., 17, 949-954 (2006)

[4] Simpson A.G., Kalli K., Zhou K., Zhang L., Bennion I., "Blank beam fabrication of regenerated type IA gratings", Meas. Sci. Technol., 15, $1665-1669$ (2004)

[5] Canning J., Sørenson H.R., Kristensen M., "Solid-state autocatalysis and oscillatory reactions in silicate glass systems”, Opt. Comm., 260, $595-600,(2006)$

[6] Simpson, G., Kalli, K., Canning, J., Lacraz, A., "Oscillatory behaviour in Type IA FBG: ruling out chemical complexity”, 24th International Conference on Optical Fibre Sensors, Proc. SPIE 9634, 96345L (28 September 2015) 